J. Clin. Chem. Clin. Biochem.

Vol. 19,1981 , pp. $441-445$

\title{
An Evaluation of Suitable Functions for the Insulin Standard Curve
}

\author{
By G. L. Atkins
}

Department of Biochemistry, University of Edinburgh Medical School, Edinburgh, Scotland

(Received August 27, 1980/January 23, 1981)

Summary: The insulin radioimmunoassay technique used for human insulin has been modified for measuring rabbit insulin (i) at lower concentrations of insulin in plasma, and (ii) more precisely.

Eleven algebraic functions were fitted in turn to fifty-three data sets. The goodness-of-fit was assessed in each case. It was concluded that a quadratic equation was the best function for the standard curve of the modified immunoassay, although this function is not necessarily the best for other different immunoassays.

\section{Bewertung geeigneter mathematischer Funktionen für die Insulin-Standardkurve}

Zusammenfassung: Der Radioimmunoassay für menschliches Insulin wurde modifiziert, um Insulin vom Kaninchen in geringeren Konzentrationen und genauer $\mathrm{zu}$ bestimmen.

Elf algebraische Funktionen wurden im Wechsel 53 Datensätzen angepaßt. Die Güte der Anpassung wurde in jedem Fall ermittelt.

Eine quadratische Gleichung wurde als beste Funktion für die Standardkurve des modifizierten Radioimmunoassay befunden, obwohl diese Funktion nicht notwendigerweise die beste für andere unterschiedliche Immunoassays ist.

\section{Introduction}

As part of a programme for investigating models of the glucose-insulin control system, we intend to use rabbits as experimental animals, and to measure their plasma insulin precisely. Because all the published methods and the assay kits commercially available for measuring insulin by radioimmunoassay are primarily intended for human insulin, it was necessary to modify the procedures to measure rabbit insulin. This was for three reasons. First, the porcine insulin standards generally used do not produce the same results as rabbit insulin standards. Secondly, insulin concentrations in rabbit plasma during fasting are lower than those for humans and are below the range of the usual standard curve. Thirdly, it was decided to restrict the range of standards so that only the steeper part of the standard curve was used in order to give better results.

Because the new method was sufficiently different from those established for measuring human insulin we could not assume that a logit equation was valid for the standard curve. It was therefore necessary to fit several algebraical functions and compare their suitability. Several authors have investigated various functions for insulin standard curves $(1,2,3)$. We have fitted many more functions and analysed the fit of each curve to the experimental data more rigorously.

Several elegant treatises have been published on how antigen-antibody systems should behave (4). Unfortunately most radioimmunoassays do not behave according to theory so it is not possible to fit theoretical standard curves to data, nor can one use simulation techniques to investigate the fit of standard curves (cf. the Michaelis-Menten equation (5)). It is necessary therefore to use empirical functions and then attempt to assess and compare their goodness-of-fit to the data (6).

\section{Methods}

Radioimmunoassay for rabbit insulin

Materials

Phosphate buffer, ( $40 \mathrm{mmol} / 1, \mathrm{pH} 7.4)$ was prepared according to Hales \& Randle (7). Rabbit insulin was a gift from the Novo Research Institute and was supplied freeze-dried $(100 \mu \mathrm{g})$ with human albumin $(1 \mathrm{mg})$. It was diluted in two stages with phosphate buffer to give the standard solutions. Insulin binding reagent and [ $^{125}$ I] insulin (bovine) was obtained from the Radiochemical Centre, Amersham. Solutions were prepared according to the suppliers' instructions. Rabbit plasma, insulin-free, was prepared according to Albano et al. (8). Buffer, for washing the filter discs, was prepared using $125 \mathrm{ml}$ horse serum (Horsc serum, No. 2; Wellcome) plus $125 \mathrm{ml}$ phosphate buffer. 
De-ionised water was used for all solutions. Plastic disposable tubes $(1 \mathrm{ml})$ were obtained from Luckham Ltd., Burgess Hill, Sussex, England. Membrane filter discs were from the Radiochemical Centre. Dioxan-based liquid scintillation fluid was prepared according to Bray (9).

\section{Method}

Six standard insulin concentrations were used: $13.6,27.3,40.9$ $54.6,68.2$ and $81.8 \mathrm{pmol} / 1$. Into a $1 \mathrm{ml}$ plastic tube were placed $100 \mu \mathrm{l}$ buffer, $50 \mu \mathrm{l}$ standard insulin solution, $150 \mu \mathrm{l}$ insulinfree plasma and $50 \mu \mathrm{l}$ insulin binding reagent. Each standard was measured in quadruplicate. The tubes were left at $4{ }^{\circ} \mathrm{C}$ for $24 \mathrm{~h}$ and then $50 \mu \mathrm{l} / 1^{125}$ I linsulin was added. After a further two days at $4^{\circ} \mathrm{C}$ the solutions were filtered through membrane filter discs by vacuum filtration and the discs washed twice with $1 \mathrm{ml}$ washing buffer at $0^{\circ} \mathrm{C}$. The filter discs were transferred to empty counting vials and dried at $120^{\circ} \mathrm{C}$ for $10 \mathrm{~min}$. Scintillation fluid $(10 \mathrm{ml})$ was added and the vials counted in a Packard Liquid Scintillation counter (model 3320) for a time such that at least 1000 counts were recorded for the highest standard, i.e. lowest count rate.

\section{Algebraic functions}

$$
\begin{aligned}
& y=\text { count } / \mathrm{min} \text { bound insulin (in presence of unlabelled } \\
& Y_{\mathrm{T}}=\frac{y}{y_{\mathrm{T}}} \times 100 \\
& y_{0}=\text { count } / \mathrm{min} \text { bound insulin (in absence of unlabelled } \\
& Y_{0}=\frac{y}{y_{0}} \times 100, \quad Y^{\prime}=1 / Y_{0} \\
& x=\text { concentration of unlabelled hormone } \mathrm{pmol} / \mathrm{l} \\
& p_{\mathrm{i}}=\text { parameters to be estimated }
\end{aligned}
$$

$a, b, c=$ general constants

\section{Functions used}

Eleven functions were used and they were arranged into a form $y=\mathrm{f}\left(p_{\mathrm{i}}, x\right)$, where $y$ (count $/ \mathrm{min}$ ) was the dependent variable and $x(\mathrm{pmol} / \mathrm{l})$ the independent variable.

\section{Two parameter}

1.1 Morgan et al. (10)

$$
y=p_{1}+p_{2} \cdot \log _{10}(x)
$$

1.2 Hyperbola (Rodbard, method 4 (11))

$$
Y^{\prime}=a+b \cdot x
$$

can be transformed into

$$
y=\frac{1}{\left(p_{1}+p_{2} \cdot x\right)}
$$

\section{Three parameter}

2.1 Quadratic

$$
y=p_{1}+p_{2} \cdot x+p_{3} \cdot x^{2}
$$

\subsection{Logit (11)}

$$
\operatorname{logit}\left(Y_{0}\right)=a+b \cdot \log _{10}(x)
$$

can be transformed into

$$
y=\frac{p_{3}}{\left(1+\exp \left\{p_{1}+p_{2} \cdot \log _{e}(x)\right\}\right)}
$$

\subsection{Hyperbola (Täljedal \& Wold (1))}

$$
\frac{1}{(y+c)}=a \cdot x+b
$$

becomes

$$
y=\frac{\left(p_{1}-x\right)}{\left(\dot{p}_{2}+p_{3} \cdot x\right)}
$$

\subsection{Exponential}

$$
y=p_{1}^{\prime}+\bar{p}_{2} \cdot \operatorname{ex} \hat{p}\left(-p_{3} \cdot x\right)
$$

\subsection{Chard (12)}

$$
Y_{\mathrm{T}}=\left[a-\sqrt{\left(a^{2}-b\right)}\right] \cdot c
$$

or,

$$
y \equiv\left[a-\sqrt{\left(a^{2}-b\right)}\right] \cdot c
$$

where,

$$
\begin{aligned}
& a=\left(p_{1}+\dot{p}_{2}+x\right) \\
& b=4 \cdot \ddot{p}_{1} \cdot x \\
& c=p_{3} / x
\end{aligned}
$$

2.6 Sigmoid (Tạljedạl \& Wold (1))

$$
y=\frac{1}{\left(p_{1} \cdot x^{p_{2}}+p_{3}\right)}
$$

3. Four parameter

3.1 Cubic

$$
y=p_{1}+p_{2} \cdot x+p_{3} \cdot x^{2}+p_{4} \cdot x^{3}
$$

3.2 Brówn et al. (13)

$$
x=a+b \cdot \log _{10}\left(Y_{\mathrm{T}}\right)+c \cdot\left[\log _{10}\left(Y_{\mathrm{T}}\right)\right]^{2}
$$

can be transformed into

$$
y=p_{4} \cdot \exp \left\{\frac{1}{\hat{2} \cdot \hat{p}_{3}}\left[\sqrt{p_{2}^{2}-4 \cdot p_{3} \cdot\left(p_{1}-x\right)}-p_{2}\right]\right\}
$$

3.3 Malan et al. (14)

$$
y=\frac{\left(p_{1}+p_{2} \cdot x+p_{3} \cdot x^{2}\right)}{\left(x+p_{4}\right)}
$$

\section{Curve fitting}

Background count rates (about 30 counits $/ \mathrm{min}$ ) were negligible compared with the count rates of the standards and were therefore not subtracted. Each count rate was use'd as a separate data point. A standard curve was fitted to 24 equally weighted points using nòn-lineár rêgreșision $(15,16)$. Recent work (MichaelisMenten equation) has shown that there is no adväntage in calculating a weighted mean of the quadruplicates and then fitting a standard curve to the six means using appropiriate weighting rather than using 24 equally weighted points (17).

\section{Model testing}

Previous assessmeñts of goodness-of fit of insulin R!̣ standard curves used mainly the F-test $(1,2,3)$. In this sürey we have used 6 tests on each curve fitted: They ate discussed in greater detail elsewhere (6) but thiey are briefly described below. The first test was to calculate the sum of square of residuals

$$
\mathrm{SSR}=\Sigma\left(y_{\text {obs }}-y_{\text {calc }}\right)^{2}
$$


where $y_{\text {obs }}$ was the experimentally observed count rate and $y_{\text {calc }}$ was the predicted value calculated by the curve fitting program. The lowcr the value of SSR, the better the goodnessof-fit. The second test plotted Rankits $v s$ the residuals $\left(y_{\text {obs }}-\right.$ $\left.y_{\text {calc }}\right)$. If the residuals were normally distributed the points lay close to a straight line. The third test plotted the residuals $v s$ the independent variable (insulini concentration) and calculated a probability $(P)$ that their distribution would have been expected from a normal distribution. This if of ten called a "Runs test". The fourth test explored the sum-of-squares surface near the minimum. Generally, only models which fit data well give a symmetrical surface at this point. The fifth test was less quantitative and concerned the nature of convergence of the non-linear regression to a solution. Experience shows that convergence is slow or difficult with a poor model. The sixth test expressed the standard deviations of the parameter estimates as percentage coefficient of variation. With a good fit these are approximately equal. The results of these six tests were considered together to give an overall assessment of goodness-of-fit.

Finally, the assessments for the curves fitted to each data set were compared and ranked according to their goodness-of-fit.

\section{Computer}

The computer programs were written in IMP (an advanced language developed in Edinburgh from Algol and Atlas Autocode) and run on the IBM 350/155 at the Edinburgh Regional Computing Centre.

\section{Results}

Fifty three sets of experimental data were obtained altogether. Figure 1 shows one of these data sets. The fitted curve is a quadratic. The eleven functions were fitted to each data set in turn. At the completion of this stage it was apparent that three of the functions fitted the data poorly. They were: no. 2.3, the hyperbola of Täljedal \& Wold (7); no. 2.6, the sigmoid of Täljedal \& Wold (1); and no. 3.2, the function of Brown et al. (13). This was apparent by the large number of occasions in which it was impossible to get the computer program to converge satisfactorily. Recently it has been pointed out to me that functions 2.2 and 2.6 are mathematically identical. If in function $2.2 p_{1}$ is replaced by $\ln \left(p_{1} / p_{3}\right)$, and $p_{3}$ by $1 / p_{3}$ then function 2.6 is obtained. However the observation that one model, with a different arrangement of parameters, should fit better than the other is not unknown in model fitting.

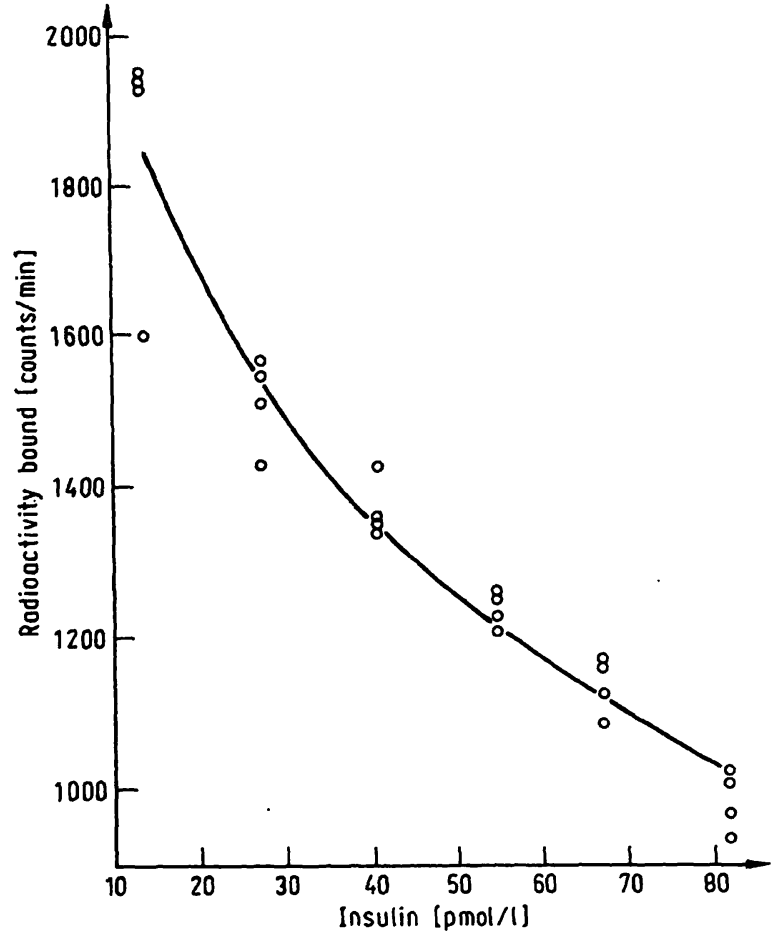

Fig. 1. A quadratic function fitted to one of the data sets. Note that the four data points at each insulin concentration appear to be widcly separated because the ordinatc has been abbreviated and expanded.

The fit of the remaining eight functions to each data set was then analysed by the model testing program. The results for one data set are given in table 1. Comparison of the fit of each function allowed the goodnessof-fit of each function to be ranked from 1 (the best) to 8 (the worst). Table 2 shows the rankings for each data set.

\section{Discussion}

Future work on modelling glucose homeostatis requires precise and accurate estimates of insulin in rabbit plasma. It has therefore been necessary to modify the existing

Tab. 1. Results of the model testing on one data set. The final rank is obtained by overall assessment of the six statistical tests.

\begin{tabular}{|c|c|c|c|c|c|c|c|c|}
\hline Function: & $\begin{array}{l}(1.1) \\
\text { Morgan } \\
\text { et al. }\end{array}$ & $\begin{array}{l}(1.2) \\
\text { Rodbard 's } \\
\text { hyperbola }\end{array}$ & $\begin{array}{l}(2.1) \\
\text { Quadratic }\end{array}$ & $\begin{array}{l}(2.2) \\
\text { Logit }\end{array}$ & $\begin{array}{l}(2.4) \\
\text { Exponential }\end{array}$ & $\begin{array}{l}(2.5) \\
\text { Chard }\end{array}$ & $\begin{array}{l}(3.1) \\
\text { Cubic }\end{array}$ & $\begin{array}{l}(3.3) \\
\text { Malan } \\
\text { et al. }\end{array}$ \\
\hline $\begin{array}{l}\text { SSR } \\
\text { Rankits plot } \\
\text { Run's test } \mathbf{P} \\
\text { Sum of squares surface } \\
\text { Convergençe } \\
\text { SD params }\end{array}$ & $\begin{array}{l}77.6 \\
\text { good } \\
0.31 \\
\text { very good } \\
\text { very good } \\
2.3 \\
5.5\end{array}$ & $\begin{array}{l}80.3 \\
\text { very poor } \\
0.74 \\
\text { good } \\
\text { slow } \\
3.1 \\
6.0\end{array}$ & $\begin{array}{l}87.2 \\
\text { very poor } \\
0.59 \\
\text { very good } \\
- \\
3.5 \\
15.9 \\
32.9\end{array}$ & $\begin{array}{l}88.5 \\
\text { poor } \\
0.11 \\
\text { very good } \\
\text { slow } \\
\text { high }\end{array}$ & $\begin{array}{l}120.9 \\
\text { good } \\
0.03 \\
\text { very good } \\
\text { very good } \\
\text { high }\end{array}$ & $\begin{array}{l}79.0 \\
\text { poor } \\
0.31 \\
\text { good } \\
\text { poor } \\
\text { very high }\end{array}$ & $\begin{array}{l}67.4 \\
\text { poor } \\
0.95 \\
\text { very good } \\
- \\
5.8 \\
24.8 \\
39.0 \\
46.1\end{array}$ & $\begin{array}{l}71.2 \\
\text { good } \\
0.64 \\
\text { good } \\
\text { very good } \\
\text { high }\end{array}$ \\
\hline Rank & 2 & 4 & 5 & 7 & 8 & 6 & 1 & 3 \\
\hline
\end{tabular}


Tab. 2. Summary of rankings. The mean of the individual ranks with S.E.M. $(n=53)$ and median is presented.

\begin{tabular}{llll}
\hline Function & Mean & S.E.M. & Median \\
\hline (1.1) Morgan et al. & 4.53 & 0.32 & 4 \\
(1.2) Rodbard 's hyperbola & 4.54 & 0.29 & 5 \\
(2.1) Quadratic & 2.87 & 0.26 & 2 \\
(2.2) Logit & 3.33 & 0.32 & 3 \\
(2.4) Exponential & 5.01 & 0.24 & 5 \\
(2.5) Chard & 6.91 & 0.22 & 8 \\
(3.1) Cubic & 3.48 & 0.28 & 3 \\
(3.3) Malan et al. & 5.33 & 0.22 & 5 \\
\hline
\end{tabular}

method, for measuring insulin in human plasma, so that it will measure insulin in the rabbit. The first.important modification is that rabbit insulin has been used as the standard. Unpublished work shows that the use of porcine insulin as a standard produces high estimates of rabbit insulin concentration, as much as $100 \%$ at some insulin concentrations. Secondly, precision has been increased by using only the steepest part of the standard curve. In practice, plasma samples may have to be diluted with plasma to bring them within the range of the abbreviated standard curve.

Because the assay has been modified there was no guarantee that the logit curve used for human insulin assays will be applicable. It was therefore necessary to determine the best function to use as a standard curve for the new assay. Many functions have been proposed for standard curves and, as far as can be ascertained, all of those published up to 1973 have been included in this survey. The number used here is greater than in previous surveys $(1,2,3)$. It would be desirable to use a theoretically derived function (e.g. Feldman et al. (4)) for the standard curve. However, in practice, binding assay curves often do not appear to obey these theories. It was therefore necessary to use empirical functions. One disadvantage of the current use of the logit curve is that the data is transformed so that a straight line can be fitted, although the logit function has been fitted directly (18). It is well known in other areas of biochemistry (c.f. the Michaelis-Menten equation, (5)) that transformation of data introduces bias into the fitting of functions, if the error is normally distributed, and will therefore lead to inaccurate results. In this survey all the functions were fitted directly by non-linear regression so that no bias was introduced, assuming a normal distribution of errors.

The problem then is to assess the goodness-of-fit to decide which, if any, of the empirical functions is the best. Täljdal \& Wold (1); Ichihara et al. (2) and Schöneshöfer (3) used principally the F-test, which is usually considered to be rather insensitive. Malan et al. (14) claimed to have applied many statistical tests in their survey of several functions, but full details of this work do not appear to have been published. The current survey is an improvement on these other studies, because a wide range of statistical tests of known reliability has been used (6).

The results shown in table 2 show that from the mean and the median of its rank a quadratic function is better than any other, although it might not be significantly better than the logit function. Next in goodness-of-fit are the logit function and the cubic function, and here there is no significant difference between the two. It is therefore proposed to use a quadratic function for the standard curve in all future work using this insulin assay.

These conclusions are not of general application to all immunoassay standard curves. A survey of the above functions for use with an immunoassay for cAMP (Atkins, unpublished) produces quite different results and indicates that an entirely different function is appropriate. Marschner, Herndl \& Scriba (19) evaluated four equations for use with ten different immunoassays. They showed that for two-thirds of the assays all four equations were equally suitable, but for the other immunoassays some equations gave better results depending mainly on the type of error likely to be present in the data. Schöneshöfer (3), also, has shown that different standard curves are required for steroid and peptide assays. It is therefore apparent that no one algebraic function can be used for each type of immunoassay. When any new immunoassay is devised, some work must be included to choose the most suitable function for the standard curve.

Since this manuscript was prepared, Marschner et al. (19) have introduced the use of spline functions for standard curves. Although these functions have been used much in physics and technology for fitting curves to data, this example of their application to immunoassays appears to be the only one so far. Their work shows that a spline function can be used with ten different types of assay and overall it is better (although sometimes only marginally) than three other types of standard curves. Spline functions may therefore be applicable more generally than most other functions used to date for immunoassay standard curves, and thus they need to be investigated more fully.

\section{Acknowledgements}

I would like to thank Miss Caroline Thompson for her expert assistance. This work was supported by a grant from the Science Rescarch Council. 


\section{References}

1. Täljedal, I.-B. \& Wold, S. (1970), Biochem. J. 119, 139-143.

2. Ichihara, K., Yamamoto, T., Kumahara, Y. \& Miyai, K. (1977), Clin. Chim. Acta 79, 331-340.

3. Schöneshöfer, M. (1977), Clin. Chim. Acta 77, 101-115.

4. Feldman, H., Rodbard, D. \& Levine, D. (1972), Anal. Biochem. 45, 530-556.

5. Atkins, G. L. \& Nimmo, 1. A. (1975), Biochem. J. 149, $775-777$.

6. Atkins, G. L. (1976), Biochem. Soc. Trans. 4, 357-361.

7. Hales, C. N. \& Randle, P. J. (1963), Biochem. J. 88, 137146.

8. Albano, J. D. M., Ekins, R. P., Maritz, G. \& Turner, R. C. (1972), Acta Endocrinol. 70, 487-509.

9. Bray, G. A. (1960), Anal. Biochem. 1, 279-285.

10. Morgan, C. R., Hardigg, J. B. \& Fisher, D. D. (1967), Diabetes 16, 734-737.

11. Rodbard, D., Bridson, W. \& Rayford, P. L. (1969), J. Lab. Clin. Med. 74, 770-781.
12. Chard, T. (1971), in Radioimmunoassay Methods (Kirkham, K. E. \& Hunter, W. M., eds.) p. 595-598. Churchill Livingstone, Edinburgh and London.

13. Brown, G. M., Boshans, R. L. \& Schalch, D. S. (1970), Comput. Biomed. Res. 3, 212-217.

14. Malan, P. G., Newman, G. B. \& Ekins, R. P. (1973), Acta Endocrinol. 73, S177, 99.

15. Atkins, G. L. (1971), Biochim. Biophys. Acta 252, 405420.

16. Atkins, G. L. (1977), Comput. Biol. Med. 7, 321-325.

17. Atkins, G. L. \& Gardner, M. L. G. (1977), Biochim. Biophys. Acta 468, 127-145.

18. Healy, M. J. R. (1972), Biochem. J. 130, 207-210.

19. Marschner, I., Herndl, R. \& Scriba, P. C. (1980), J. Clin. Chem. Clin. Biochem. 18, 105-109.

Dr. Gordon L. Atkins

Dept. Biochemistry

University of Edinburgh Med. School

Teviot Place

Edinburgh EH 89 AG

Scotland 
